Corrigendum

\title{
Corrigendum to "Analysis of the Seismic Performance of Site-Bolted Beam to Column Connections in Modularized Prefabricated Steel Structures"
}

\author{
Xuechun Liu $\mathbb{D}^{1},{ }^{1,2,3}$ Xiaoxiong Cui, ${ }^{1}$ Zhiwei Yang, ${ }^{1}$ and Xinxin Zhan ${ }^{1}$ \\ ${ }^{1}$ Beijing Engineering Research Center of High-Rise and Large-Span Prestressed Steel Structures, Beijing University of Technology, \\ Beijing 100124, China \\ ${ }^{2}$ Beijing Key Laboratory of Earthquake Engineering and Structural Retrofit, Beijing University of Technology, \\ Beijing 100124, China \\ ${ }^{3}$ Beijing Advanced Innovation Centre for Future Urban Design, Beijing 100044, China
}

Correspondence should be addressed to Xuechun Liu; liuxuechun@bjut.edu.cn

Received 2 June 2021; Accepted 2 June 2021; Published 14 June 2021

Copyright (c) 2021 Xuechun Liu et al. This is an open access article distributed under the Creative Commons Attribution License, which permits unrestricted use, distribution, and reproduction in any medium, provided the original work is properly cited.

In the article titled "Analysis of the Seismic Performance of Site-Bolted Beam to Column Connections in Modularized Prefabricated Steel Structures" [1], the fund number for the "National Key Research and Development Program of China" was given incorrectly in Acknowledgments section. The corrected section appears below.

\section{Acknowledgments}

The authors gratefully acknowledge the support for this work, which was funded by the National Key Research and Development Program of China (2016YFC0701503), the National Natural Science Foundation of China (51678010), the Beijing Municipal Natural Science Foundation (8172009), and the Beijing Municipal Science and Technology Plan Program (Z171100002217017).

\section{References}

[1] X. Liu, X. Cui, Z. Yang, and X. Zhan, "Analysis of the Seismic Performance of Site-Bolted Beam to Column Connections in Modularized Prefabricated Steel Structures," Advances in Materials Science and Engineering, vol. 2017, Article ID 1932730, 18 pages, 2017. 